Journal of Engineering and Applied Sciences 15 (5): 1089-1097, 2020

ISSN: 1816-949X

(C) Medwell Journals, 2020

\title{
Risk Analysis on the Causes of Safety Accident at Construction Site in Korea using Eigenvector
}

\author{
Jong-Sik Lee \\ Department of Architectural Engineering, Songwon University, 73 Songam-ro, \\ 61756 Nam-gu, Gwangju Metropolitan City, Republic of Korea
}

\begin{abstract}
In this study, the causes of safety accident in construction site were derived and the risk of the causes of safety accidents was analyzed. First, the causes of safety accident at the construction site in Korea from 2016-2018 were analyzed to identify the causes of safety accident. The causes of safety accident were classified into 4M technique (Man, Machine, Media and Management) which is safety management technique. The risk of man, machine, media and management was analyzed using the eigenvector method and the risk of the causes of safety accident was analyzed. Using the risk of man, machine, media and management and the risk of the causes of safety accident, the final risk of the causes of safety accident was calculated. The risk of safety accident due to breaches of safety regulations or guidelines', 'inappropriate communication with worker's, 'inadequate construction method plans', 'lack of training and education of personnel' and 'inadequate recognition and evaluation of site hazards' was analyzed to be high. All of the causes of safety accident with high-risk were analyzed as belonging to management. Therefore, safety management activities in terms of management are necessary to prevent safety accidents. In addition, by improving safety management activities for the causes of safety accident with high-risk, the effectiveness of safety management activities can be improved and safety accident can be prevented.
\end{abstract}

Key words: Construction safety, safety management, cause of safety accident, risk, media and management, eigenvector

\section{INTRODUCTION}

Background and purpose of the study: In 2018, the number of safety accidents caused by industrial accidents in Korea is 25,649 in construction, 25,333 in manufacturing, 4,237 in transportation, warehousing and communication service, 1,897 in mining, 1,124 in forestry and 87 in electricity and gas water supply. The number of safety accident victims in the construction industry is the largest. The number of safety accidents that occurred at the construction site in Korea over the past 3 years increased to 23,669 in 2016, 25,132 in 2017 and 25,649 in 2018. In addition, among the safety accidents in Korea in 2018, the number of deaths by industry was 579 in construction, 433 in manufacturing, 121 in transportation, warehousing and communication service, 457 in mining, 16 in forestry and 4 in electricity and gas water supply (MEL., 2019). As such, the death toll in the construction industry is more than $35.9 \%$. Safety accident occurring at the construction site is caused by complex causes throughout the entire process of ordering, design and construction. Also in recent years, the causes of safety accident have been diversified due to the introduction of advanced construction methods, diversification of process and workplace conditions and changes in the characteristics of workers. Due to such changes of the construction environment, activities for predicting and preventing safety accident occurring at the construction site are becoming more difficult. Safety management refers to management technique to prevent accidents by anticipating risk factors in advance. It is involved in the entire process of the construction project (Park, 2010). It is important to develop a safety management system that will be highly effective in reducing workplace disasters. The safety management system should rely simply on experienced management and post management but it should also be able to prevent accidents by eliminating harmful factors and risks by identifying potential risks (Seo, 2013). Therefore, it is necessary to estimate the risks of identified risk factors during work and to establish countermeasures for improvement of those risks, so as to achieve effective safety management (Matthews and Ageros, 2008). However, safety management in the construction site focusing on examples of accidents and preventive measures as well as risk assessment about potential accidents has not yet been implemented (Paek and Cho, 2015). In this study, the causes of safety accident in the construction site were derived and the risk of the causes of safety accident was analyzed. Through this, it is intended to provide basic data that can be used to establish a safety accident prevention plan in the construction site. 


\section{J. Eng. Applied Sci., 15 (5): 1089-1097, 2020}

Scope and method of study: The scope of this study is to derive the causes of safety accident occurring at the construction site and to derive the risk of the causes of each safety accident. The methods and procedures of this study are as follows.

Analyze the causes of safety accident occurring at the construction site. The causes of safety accident were classified into 4 items of $4 \mathrm{M}$ technique (Man, Machine, Media and Management) according to their characteristics. Design the risk analysis model using eigenvectors. Calculate the risk of the $4 \mathrm{M}$ items and the risk of the causes of safety accident. Then, the final risk is calculated using the risk of the $4 \mathrm{M}$ item and the risk of the causes of safety accident. Identify the causes of safety accident that require centralized management according to the degree of risk. And summarize the result of the study.

\section{MATERIALS AND METHODS}

\section{Risk analysis model}

Composition of $4 \mathrm{M}$ items and causes of safety accident: Risk analysis identifies the causes of safety accident that may occur in the work for risk analysis. Measures are taken to minimize the likelihood that the causes of safety accident can develop into an accident. The $4 \mathrm{M}$ technique used for risk analysis classifies the causes of safety accident into four items, man, machine, management and media as shown in Table 1 (MEL., 2019). The causes of safety accident corresponding to human risk that lead to unsafe behavior of workers correspond to man. The causes of safety accident corresponding to the physical risk that causes unsafe condition correspond to machine. The causes of safety accident corresponding to the administrative flaws that cause the accident correspond to management. The causes of safety accident corresponding to the working environment such as noise, dust and harmful substances correspond to media.

As a result of analyzing safety accident data at the construction site from 2016-2018 provided by the construction safety management information system operated by the Korean government, there are 49 causes of safety accident occurred at the construction site from 2016-2018 as shown in Table 2.

Commissioned by four experts in the field of construction safety, 49 causes of safety accident in Table 1 were classified into $4 \mathrm{M}$ items according to their characteristics. A plurality of $4 \mathrm{M}$ items can be selected according to the characteristics of the cause of safety accident and a $4 \mathrm{M}$ item having a large number of selections was determined as the final $4 \mathrm{M}$ item.

As shown in Table 3, 25 causes of safety accident corresponding to management were the most. Next, 10 causes of safety accident correspond to man. It was analyzed that 7 causes of safety accident corresponded to media and 6 causes of safety accident corresponded to
Table 1: Characteristics of $4 \mathrm{M}$ items

\begin{tabular}{ll}
\hline 4M items & Contents \\
\hline Man & $\begin{array}{l}\text { Human risk assessment that generates } \\
\text { the unsafe behavior }\end{array}$ \\
Machine & $\begin{array}{l}\text { Physical risk assessment that generates } \\
\text { the unsafe condition } \\
\text { Evaluation defects administrative to } \\
\text { Management }\end{array}$ \\
Media & $\begin{array}{l}\text { Workplace assessment noise, dust } \\
\text { and toxic substances }\end{array}$ \\
\hline
\end{tabular}

machine. 'Inappropriate use of personal protective equipment (A30)' was judged by experts 2,3 and 4 as the cause of safety accident for man. And expert 1 judged 'Inappropriate use of personal protective equipment (A30)' as the cause of safety accident for two $4 \mathrm{M}$ items, Man and Management. Hence, 'Inappropriate use of personal protective equipment (A30)' is classified as the cause of safety accident for man with a large number of choices. 'Operation of defective machinery, equipment and tools (A41)' was judged by experts A, C and D as the cause of safety accident for machine. Expert B judged 'Operation of defective machinery, equipment and tools (A41)' as the cause of safety accident for management. Thus, 'Operation of defective machinery, equipment and tools (A41)' is classified as the cause of safety accident for machine with a large number of choices. Table 3 shows data classified by $4 \mathrm{M}$ items according to the characteristics of causes of safety accident.

Design of risk analysis model: A risk analysis model was designed for the causes of safety accident occurring at $4 \mathrm{M}$ items and construction sites. The eigenvector method was used to design the risk analysis model.

The eigenvector method uses the characteristics of pairwise comparison matrix and eigenvector (Saaty and $\mathrm{Hu}, 1998$ ). In this study, the eigenvector corresponding to the maximum value among the eigen values of the pairwise comparison matrix was used as the risk. Analyze the relative risk between items from the defined pairwise comparison matrix. Then, the eigenvector for each item is calculated (Fig. 1).

The eigenvector of the items in row $i$ and column $j$ of pairwise comparison matrix can be calculated by dividing the pairwise comparison value in row $i$ and column $j$ by all pairwise comparison values in column $\mathrm{j}$. The risk can be calculated by arithmetically averaging the eigenvector of calculated row $i$. Therefore, the eigenvector of item $\mathrm{k}$ located in row $i$ and column $j$ is defined as in Eq. 1. The formula of risk calculation is defined as Eq. 2:

$$
\begin{aligned}
& E_{i j}=\frac{W_{i j}}{\sum_{j-1}^{n} w_{j}} \\
& R_{k}=\frac{\sum_{i=1}^{n} E_{j}}{N}
\end{aligned}
$$


Table 2: Causes of safety accident occurred at the construction site (2016 2018)

\begin{tabular}{|c|c|}
\hline Accident codes & Causes of safety accident \\
\hline A01 & Performing work in unsafe positions \\
\hline $\mathrm{A} 02$ & Performing work with inadequate communication between supervisors and workers \\
\hline A03 & Creation of alternative design without consideration of construction method or construction procedure \\
\hline A04 & Failure to assess adverse effects on work caused by deterioration due to weather conditions \\
\hline A05 & Performing work in judgment mistakes, underestimation and overestimation \\
\hline A06 & Improper maintenance of machinery, equipment and tools \\
\hline A07 & Inadequate communication with workers \\
\hline A08 & Inadequate conditions above ground and underground \\
\hline A09 & Inadequate topography \\
\hline A10 & Inappropriate control of underground utilities \\
\hline A11 & Inappropriate control of working system \\
\hline A12 & Inappropriate control of workplace environment (light, noise, temperature, humidity, air, etc.) \\
\hline A13 & Inappropriate design of entry structures \\
\hline A14 & Inappropriate entry and exit from workplace \\
\hline A15 & Inappropriate environmental management of workplace \\
\hline A16 & Inappropriate installation plan for safety facilities \\
\hline A17 & Inappropriate instructions from managers to construction workers \\
\hline A18 & Inappropriate loading and handling of materials \\
\hline A19 & Inappropriate maintenance of temporary structure \\
\hline A20 & Inappropriate management of hazardous chemicals or toxic substances \\
\hline A21 & Inappropriate method statement \\
\hline A22 & Inappropriate plan for machinery and equipment use \\
\hline A23 & Inappropriate plan for site deployment such as manpower, machinery, equipment, etc. \\
\hline A24 & Inappropriate recognition and assessment of on-site risk factors \\
\hline A25 & Inappropriate site deployment of manpower, machinery, equipment, etc. \\
\hline A26 & Inappropriate structural design for installation of machinery, equipment, etc. \\
\hline A27 & Inappropriate structural design of temporary structure \\
\hline A28 & Inappropriate use of machinery and equipment while in operation \\
\hline A29 & Inappropriate use of machinery, equipment and tools \\
\hline A30 & Inappropriate use of personal protective equipment \\
\hline A31 & In appropriate use of safety facilities or personal protective equipment \\
\hline A32 & In appropriate use of working tools \\
\hline A33 & Inappropriate work plan \\
\hline A34 & Instability of temporary structure \\
\hline A35 & Lack of experience designing projects \\
\hline A36 & Lack of training and education on manpower needs \\
\hline A37 & Lack of understanding of designer's methods and procedures \\
\hline A38 & Omission of standard safety work procedures \\
\hline A39 & Operating a construction site with inappropriate work procedures \\
\hline A40 & Operation of an inappropriate temporary structure \\
\hline A41 & Operation of defective machinery, equipment and tools \\
\hline A42 & Performing work while lacking proficiency in the task \\
\hline A43 & Performing work in a state of non-compliance with safety regulations \\
\hline A44 & Performing work with physical disabilities \\
\hline A45 & Unfavorable climate conditions \\
\hline A46 & Unsafe behavior by workers \\
\hline A47 & Unsafe work behavior \\
\hline A48 & Unsafe work conditions caused by inadequate or missing safety facilities \\
\hline A49 & Violation of safety regulations and guidelines \\
\hline
\end{tabular}

Table 3: Causes of safety accident by $4 \mathrm{M}$ items

\begin{tabular}{ll}
\hline 4M items/Accident code & Causes of safety accident \\
\hline A01 & Performing work in unsafe positions \\
A05 & Performing work in judgment mistakes, underestimation and overestimation \\
A30 & Inappropriate use of personal protective equipment \\
A38 & Omission of standard safety work procedures \\
A42 & Performing work while lacking proficiency in the task \\
A43 & Performing work in a state of non-compliance with safety regulations \\
A44 & Performing work with physical disabilities \\
A46 & Unsafe behavior by workers \\
A47 & Unsafe work behavior \\
A48 & Unsafe work conditions caused by inadequate or missing safety facilities \\
Machine & \\
A06 & Improper maintenance of machinery, equipment and tools \\
A22 & Inappropriate plan for machinery and equipment use \\
A26 & Inappropriate structural design for installation of machinery, equipment, etc. \\
\hline
\end{tabular}


Table 3: Continue 4M items/Accident code

Management

$\mathrm{A} 02$

A04

A07

A10

A11

A13

A14

A15

A16

A17

A18

A19

A21

A23

A24

A25

A27

A31

A32

A33

A34

A35

A36

A39

A40

A49

Media

A03

A08

A09

$\mathrm{A} 12$

A20

A37

A45

Causes of safety accident

Inappropriate use of machinery and equipment while in operation

Inappropriate use of machinery, equipment and tools

Operation of defective machinery, equipment and tools

Performing work with inadequate communication between supervisors and workers

Failure to assess adverse effects on work caused by deterioration due to weather conditions

Inadequate communication with workers

Inappropriate control of underground utilities

Inappropriate control of working system

Inappropriate design of entry structures

Inappropriate entry and exit from workplace

Inappropriate environmental management of workplace

Inappropriate installation plan for safety facilities

Inappropriate instructions from managers to construction workers

Inappropriate loading and handling of materials

Inappropriate maintenance of temporary structure

Inappropriate method statement

Inappropriate plan for site deployment such as manpower, machinery, equipment etc.

Inappropriate recognition and assessment of on-site risk factors

Inappropriate site deployment of manpower, machinery, equipment etc.

Inappropriate structural design of temporary structure

Inappropriate use of safety facilities or personal protective equipment

Inappropriate use of working tools

Inappropriate work plan

Instability of temporary structure

Lack of experience designing projects

Lack of training and education on manpower needs

Operating a construction site with inappropriate work procedures

Operation of an inappropriate temporary structure

Violation of safety regulations and guidelines

Creation of alternative design without consideration of construction method or construction procedure Inadequate conditions above ground and underground

Inadequate topography

Inappropriate control of workplace environment (light, noise, temperature, humidity, air, etc.)

Inappropriate management of hazardous chemicals or toxic substances

Lack of understanding of designer's methods and procedures

Unfavorable climate conditions

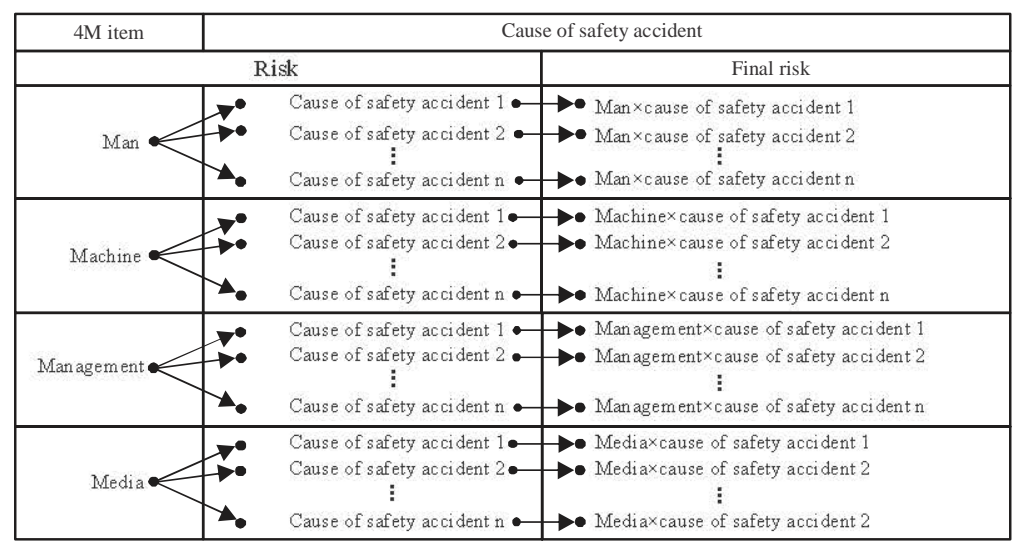

Fig. 1: Final risk calculation method

Where:

$\mathrm{R}_{\mathrm{k}}$ : The risk of item $\mathrm{k}$

$\mathrm{N}$ : The size of the pairwise comparison matrix (the number of items in pairwise comparison)

$E_{i j}$ : The eigenvector of row $i$ and column $j$

$\mathrm{E}$ : The eigenvector of the pairwise comparison matrix
$\mathrm{R}$ : The risk, $\mathrm{w}$ is the pairwise comparison value

$\mathrm{k}$ : The item, $\mathrm{j}$ is the column vector

I : The row vector

Define $4 \mathrm{M}$ items in the upper class and 49 causes of safety accident in the lower class. Analyze the risk of $4 \mathrm{M}$ 
items and 49 causes of safety accident. First, compare the relative risk between $4 \mathrm{M}$ items using a two-point scale (risk $=2$, equal risk $=1$, inverse of the given value if the opposite). Next, compare the relative risk between the causes of safety accident by $4 \mathrm{M}$ items using a two-point scale (risk $=2$, equal risk $=1$, inverse of the given value if the opposite). Then, the final risk by causes of safety accident is calculated by multiplying the risk of the $4 \mathrm{M}$ item in the upper class by the risk of the causes of safety accident in the lower class. Figure 1 illustrates the final risk calculation method.

\section{RESULTS AND DISCUSSION}

\section{Risk analysis}

Risk analysis of $4 \mathrm{M}$ items: Four experts in the field of construction safety were commissioned to compare the relative risk between the $4 \mathrm{M}$ items Table 4 . The eigenvector of $4 \mathrm{M}$ items were substituted into Eq. 2 to calculate the risk of $4 \mathrm{M}$ items Table 5. The risk of management was analyzed to be the highest with 1.63 . The risk of man was 0.96 , the risk of machine was 0.82 and the risk of media was 0.69 . Table 4 shows the eigenvector calculated by the pairwise comparison of the risk of $4 \mathrm{M}$ items. Table 5 shows the risk of $4 \mathrm{M}$ items calculated using the eigenvector in Table 4.

Risk analysis of the causes of safety accident by $4 \mathrm{M}$ items: Risk of the causes of safety accidents of each 4M item was analyzed.

Risk of the causes of safety accident in man: The risk of A47 is the highest with 1.34. Next, the risk of A48 is 1.26 , the risk of $\mathrm{A} 30$ is 1.25 , the risk of $\mathrm{A} 43$ is 1.1 , the risk of $\mathrm{A} 38$ is 1.09 , the risk of $\mathrm{A} 46$ is 1.05 , the risk of $\mathrm{A} 01$ is 0.85 , the risk of $\mathrm{A} 05$ is 0.78 , the risk of $\mathrm{A} 42$ is 0.73 and the risk of A44 was 0.56 .

Table 6 shows the eigenvector calculated by comparing the degree of risk of the causes of safety accident belonging to man. Table 7 shows the risk of the causes of safety accident belonging to man calculated using the eigenvector of Table 6 .

Risk of the causes of safety accident in machine: The risks of A28 and A29 are the highest with 1.32. Next, the risk of A41 was 1.21, the risk of A22 was 0.77 , the risk of $\mathrm{A} 02$ was 0.70 and the risk of $\mathrm{A} 26$ was 0.66 . The following Table 8 is the eigenvector calculated by the pairwise comparison of the risk of the causes of safety accident in machine.

Table 9 shows the risk of the causes of safety accident belonging to machine calculated using the eigenvector in Table 8.

Table 4: Pairwise comparison and eigenvector of $4 \mathrm{M}$ items

\begin{tabular}{lcccc}
\hline & Man & Machine & Management & Media \\
\hline Man & 1.0 & 1.0 & 0.5 & 2.0 \\
Machine & 1.0 & 1.0 & 0.5 & 1.0 \\
Management & 2.0 & 2.0 & 1.0 & 2.0 \\
Media & 0.5 & 1.0 & 0.5 & 1.0 \\
Eigenvector (E) & 4.5 & 5.0 & 2.5 & 6.0 \\
\hline
\end{tabular}

Table 5: Risk calculation data of 4M items

\begin{tabular}{lccccc}
\hline Variables & Man & Machine & Management & Media & Risk (R) \\
\hline Man & 0.22 & 0.20 & 0.20 & 0.33 & 0.96 \\
Machine & 0.25 & 0.20 & 0.20 & 0.17 & 0.82 \\
Management & 0.50 & 0.40 & 0.40 & 0.33 & 1.63 \\
Media & 0.22 & 0.20 & 0.20 & 0.33 & 0.96 \\
\hline
\end{tabular}

Table 6: Pairwise comparison and eigenvector of the causes of safety accident in man

\begin{tabular}{|c|c|c|c|c|c|c|c|c|c|c|}
\hline Accident codes & $\mathrm{A} 01$ & $\mathrm{~A} 05$ & $\mathrm{~A} 30$ & A38 & $\mathrm{A} 42$ & $\mathrm{~A} 43$ & $\mathrm{~A} 44$ & A46 & $\mathrm{A} 47$ & $\mathrm{~A} 48$ \\
\hline$\overline{\mathrm{A} 01}$ & 1.0 & 1.0 & 0.5 & 0.5 & 1.0 & 1.0 & 2.0 & 1.0 & 0.5 & 1.0 \\
\hline A05 & 1.0 & 1.0 & 0.5 & 1.0 & 1.0 & 0.5 & 2.0 & 1.0 & 0.5 & 0.5 \\
\hline A30 & 2.0 & 2.0 & 1.0 & 1.0 & 2.0 & 1.0 & 2.0 & 1.0 & 1.0 & 1.0 \\
\hline A38 & 2.0 & 1.0 & 1.0 & 1.0 & 2.0 & 1.0 & 1.0 & 2.0 & 0.5 & 0.5 \\
\hline A42 & 1.0 & 1.0 & 0.5 & 0.5 & 1.0 & 1.0 & 2.0 & 0.5 & 0.5 & 0.5 \\
\hline A43 & 1.0 & 2.0 & 1.0 & 1.0 & 1.0 & 1.0 & 2.0 & 1.0 & 1.0 & 1.0 \\
\hline A44 & 0.5 & 0.5 & 0.5 & 1.0 & 0.5 & 0.5 & 1.0 & 0.5 & 0.5 & 0.5 \\
\hline A46 & 1.0 & 1.0 & 1.0 & 0.5 & 2.0 & 1.0 & 2.0 & 1.0 & 1.0 & 1.0 \\
\hline A47 & 2.0 & 2.0 & 1.0 & 2.0 & 2.0 & 1.0 & 2.0 & 1.0 & 1.0 & 1.0 \\
\hline A 48 & 1.0 & 2.0 & 1.0 & 2.0 & 2.0 & 1.0 & 2.0 & 1.0 & 1.0 & 1.0 \\
\hline Eigenvector (E) & 12.5 & 13.5 & 8.0 & 10.5 & 14.5 & 9.0 & 18.0 & 10.0 & 7.5 & 8.0 \\
\hline
\end{tabular}

Table 7: Risk calculation data of the causes of safety accident in man

\begin{tabular}{lllllllllllll}
\hline Accident codes & A01 & A05 & A30 & A38 & A42 & A43 & A44 & A46 & A47 & A48 & Risk (R) \\
\hline A01 & 0.08 & 0.07 & 0.06 & 0.05 & 0.07 & 0.11 & 0.11 & 0.10 & 0.07 & 0.13 & 0.85 \\
A05 & 0.08 & 0.07 & 0.06 & 0.10 & 0.07 & 0.06 & 0.11 & 0.10 & 0.07 & 0.06 & 0.78 \\
A30 & 0.16 & 0.15 & 0.13 & 0.10 & 0.14 & 0.11 & 0.11 & 0.10 & 0.13 & 0.13 & 1.25 \\
A38 & 0.16 & 0.07 & 0.13 & 0.10 & 0.14 & 0.11 & 0.06 & 0.20 & 0.07 & 0.06 & 1.09 \\
A42 & 0.08 & 0.07 & 0.06 & 0.05 & 0.07 & 0.11 & 0.11 & 0.05 & 0.07 & 0.06 & 0.73 \\
A43 & 0.08 & 0.15 & 0.13 & 0.10 & 0.07 & 0.11 & 0.11 & 0.10 & 0.13 & 0.13 \\
A44 & 0.04 & 0.04 & 0.06 & 0.10 & 0.03 & 0.06 & 0.06 & 0.05 & 0.07 & 0.06 & 0.56 \\
A46 & 0.08 & 0.07 & 0.13 & 0.05 & 0.14 & 0.11 & 0.11 & 0.10 & 0.13 & 0.13 & 1.05 \\
A47 & 0.16 & 0.15 & 0.13 & 0.19 & 0.14 & 0.11 & 0.11 & 0.10 & 0.13 & 0.13 & 1.34 & 0.11 \\
A48 & 0.08 & 0.15 & 0.13 & 0.19 & 0.14 & 0.11 & 0.11 & 0.10 & 0.13 & 0.13 & 1.26 \\
\hline
\end{tabular}


J. Eng. Applied Sci., 15 (5): 1089-1097, 2020

Table 8: Pairwise comparison and eigenvector of the causes of safety accident in machine

\begin{tabular}{|c|c|c|c|c|c|c|c|}
\hline Accident codes & $\mathrm{A} 06$ & A22 & A26 & & A28 & A29 & $\mathrm{A41}$ \\
\hline A06 & 1.0 & 0.5 & 1.0 & & 0.5 & 0.5 & 1.0 \\
\hline A22 & 2.0 & 1.0 & 1.0 & & 0.5 & 0.5 & 0.5 \\
\hline A26 & 1.0 & 1.0 & 1.0 & & 0.5 & 0.5 & 0.5 \\
\hline A28 & 2.0 & 2.0 & 2.0 & & 1.0 & 1.0 & 1.0 \\
\hline A29 & 2.0 & 2.0 & 2.0 & & 1.0 & 1.0 & 1.0 \\
\hline A41 & 1.0 & 2.0 & 2.0 & & 1.0 & 1.0 & 1.0 \\
\hline Eigenvector (E) & 9.0 & 8.5 & 9.0 & & 4.5 & 4.5 & 5.0 \\
\hline Accident codes & A06 & A22 & A26 & A28 & A29 & A41 & Risk (R) \\
\hline $\mathrm{A} 02$ & 0.11 & 0.06 & 0.11 & 0.11 & 0.11 & 0.20 & 0.70 \\
\hline $\mathrm{A} 22$ & 0.22 & 0.12 & 0.11 & 0.11 & 0.11 & 0.10 & 0.77 \\
\hline A26 & 0.11 & 0.12 & 0.11 & 0.11 & 0.11 & 0.10 & 0.66 \\
\hline A28 & 0.22 & 0.24 & 0.22 & 0.22 & 0.22 & 0.20 & 1.32 \\
\hline A29 & 0.22 & 0.24 & 0.22 & 0.22 & 0.22 & 0.20 & 1.32 \\
\hline A41 & 0.11 & 0.24 & 0.22 & 0.22 & 0.22 & 0.20 & 1.21 \\
\hline
\end{tabular}

Table 10: Pairwise comparison and eigenvector of the causes of safety accident in management

\begin{tabular}{|c|c|c|c|c|c|c|c|c|c|c|c|c|c|c|c|c|c|c|c|c|c|c|c|c|c|c|}
\hline $\begin{array}{l}\text { Accident } \\
\text { codes }\end{array}$ & $\mathrm{A} 02$ & A04 & $\mathrm{A} 07$ & $\mathrm{~A} 10$ & A11 & A13 & A14 & A15 & A16 & A17 & A18 & A19 & A21 & A23 & A24 & A25 & A27 & A31 & A32 & A33 & A34 & A35 & A36 & A39 & $\mathrm{A} 40$ & A49 \\
\hline $\mathrm{A} 02$ & 1.0 & 2.0 & 1.0 & 2.0 & 1.0 & 2.0 & 2.0 & 1.0 & 1.0 & 0.5 & 1.0 & 1.0 & 0.5 & 0.5 & 1.0 & 0.5 & 0.5 & 0.5 & 2.0 & 0.5 & 2.0 & 1.0 & 0.5 & 1.0 & 0.5 & 0.5 \\
\hline A04 & 0.5 & 1.0 & 0.5 & 0.5 & 0.5 & 0.5 & 0.5 & 0.5 & 0.5 & 0.5 & 0.5 & 0.5 & 0.5 & 0.5 & 0.5 & 0.5 & 0.5 & 0.5 & 0.5 & 0.5 & 0.5 & 1.0 & 0.5 & 0.5 & 0.5 & 0.5 \\
\hline $\mathrm{A} 07$ & 1.0 & 2.0 & 1.0 & 2.0 & 2.0 & 2.0 & 1.0 & 1.0 & 1.0 & 2.0 & 2.0 & 2.0 & 2.0 & 1.0 & 2.0 & 2.0 & 2.0 & 1.0 & 2.0 & 2.0 & 2.0 & 1.0 & 2.0 & 1.0 & 2.0 & 1.0 \\
\hline A10 & 0.5 & 2.0 & 0.5 & 1.0 & 1.0 & 1.0 & 0.5 & 0.5 & 0.5 & 0.5 & 1.0 & 1.0 & 0.5 & 0.5 & 0.5 & 1.0 & 1.0 & 0.5 & 0.5 & 0.5 & 0.5 & 0.5 & 0.5 & 0.5 & 0.5 & 0.5 \\
\hline A11 & 1.0 & 2.0 & 0.5 & 1.0 & 1.0 & 1.0 & 1.0 & 1.0 & 1.0 & 1.0 & 1.0 & 1.0 & 1.0 & 1.0 & 1.0 & 1.0 & 1.0 & 1.0 & 1.0 & 1.0 & 0.5 & 1.0 & 1.0 & 1.0 & 1.0 & 1.0 \\
\hline A13 & 0.5 & 2.0 & 0.5 & 1.0 & 1.0 & 1.0 & 0.5 & 0.5 & 0.5 & 0.5 & 0.5 & 1.0 & 0.5 & 0.5 & 0.5 & 0.5 & 1.0 & 0.5 & 0.5 & 0.5 & 0.5 & 0.5 & 0.5 & 0.5 & 0.5 & 0.5 \\
\hline A14 & 0.5 & 2.0 & 0.5 & 2.0 & 1.0 & 2.0 & 1.0 & 1.0 & 0.5 & 0.5 & 1.0 & 0.5 & 0.5 & 0.5 & 0.5 & 0.5 & 0.5 & 1.0 & 0.5 & 0.5 & 1.0 & 2.0 & 0.5 & 1.0 & 1.0 & 0.5 \\
\hline A15 & 1.0 & 2.0 & 1.0 & 2.0 & 1.0 & 2.0 & 1.0 & 1.0 & 1.0 & 1.0 & 1.0 & 1.0 & 0.5 & 1.0 & 0.5 & 1.0 & 2.0 & 0.5 & 2.0 & 0.5 & 1.0 & 1.0 & 0.5 & 1.0 & 1.0 & 0.5 \\
\hline A16 & 1.0 & 2.0 & 1.0 & 2.0 & 1.0 & 2.0 & 2.0 & 1.0 & 1.0 & 1.0 & 2.0 & 1.0 & 1.0 & 1.0 & 1.0 & 1.0 & 1.0 & 1.0 & 2.0 & 1.0 & 2.0 & 2.0 & 1.0 & 1.0 & 1.0 & 0.5 \\
\hline A17 & 2.0 & 2.0 & 1.0 & 2.0 & 1.0 & 2.0 & 2.0 & 1.0 & 1.0 & 1.0 & 2.0 & 2.0 & 1.0 & 1.0 & 1.0 & 1.0 & 1.0 & 1.0 & 2.0 & 1.0 & 2.0 & 1.0 & 0.5 & 1.0 & 1.0 & 0.5 \\
\hline A18 & 1.0 & 2.0 & 0.5 & 1.0 & 1.0 & 2.0 & 1.0 & 1.0 & 0.5 & 0.5 & 1.0 & 0.5 & 0.5 & 1.0 & 0.5 & 1.0 & 1.0 & 0.5 & 2.0 & 0.5 & 1.0 & 0.5 & 0.5 & 0.5 & 1.0 & 0.5 \\
\hline A19 & 1.0 & 2.0 & 0.5 & 1.0 & 1.0 & 1.0 & 2.0 & 1.0 & 1.0 & 0.5 & 2.0 & 1.0 & 0.5 & 0.5 & 0.5 & 0.5 & 1.0 & 0.5 & 1.0 & 0.5 & 1.0 & 0.5 & 0.5 & 0.5 & 1.0 & 0.5 \\
\hline A21 & 2.0 & 2.0 & 0.5 & 2.0 & 1.0 & 2.0 & 2.0 & 2.0 & 1.0 & 1.0 & 2.0 & 2.0 & 1.0 & 2.0 & 2.0 & 2.0 & 2.0 & 2.0 & 2.0 & 2.0 & 2.0 & 1.0 & 1.0 & 1.0 & 2.0 & 0.5 \\
\hline A23 & 2.0 & 2.0 & 1.0 & 2.0 & 1.0 & 2.0 & 2.0 & 1.0 & 1.0 & 1.0 & 1.0 & 2.0 & 0.5 & 1.0 & 0.5 & 1.0 & 1.0 & 1.0 & 1.0 & 2.0 & 1.0 & 1.0 & 0.5 & 0.5 & 1.0 & 0.5 \\
\hline A24 & 1.0 & 2.0 & 0.5 & 2.0 & 1.0 & 2.0 & 2.0 & 2.0 & 1.0 & 1.0 & 2.0 & 2.0 & 0.5 & 2.0 & 1.0 & 2.0 & 2.0 & 2.0 & 2.0 & 1.0 & 2.0 & 1.0 & 1.0 & 1.0 & 2.0 & 1.0 \\
\hline A25 & 2.0 & 2.0 & 0.5 & 1.0 & 1.0 & 2.0 & 2.0 & 1.0 & 1.0 & 1.0 & 1.0 & 2.0 & 0.5 & 1.0 & 0.5 & 1.0 & 0.5 & 1.0 & 0.5 & 1.0 & 1.0 & 0.5 & 0.5 & 2.0 & 1.0 & 0.2 \\
\hline A27 & 2.0 & 2.0 & 0.5 & 1.0 & 1.0 & 1.0 & 2.0 & 0.5 & 1.0 & 1.0 & 1.0 & 1.0 & 0.5 & 1.0 & 0.5 & 2.0 & 1.0 & 2.0 & 2.0 & 1.0 & 2.0 & 1.0 & 1.0 & 2.0 & 1.0 & 0.5 \\
\hline A31 & 2.0 & 2.0 & 0.5 & 2.0 & 1.0 & 2.0 & 1.0 & 2.0 & 1.0 & 1.0 & 2.0 & 2.0 & 0.5 & 1.0 & 0.5 & 1.0 & 0.5 & 1.0 & 1.0 & 0.5 & 1.0 & 1.0 & 0.5 & 0.5 & 1.0 & 0.5 \\
\hline A32 & 0.5 & 2.0 & 0.5 & 2.0 & 1.0 & 2.0 & 2.0 & 0.5 & 0.5 & 0.5 & 0.5 & 1.0 & 0.5 & 1.0 & 0.5 & 2.0 & 0.5 & 1.0 & 1.0 & 1.0 & 1.0 & 1.0 & 0.5 & 0.5 & 1.0 & 0.5 \\
\hline A33 & 2.0 & 2.0 & 0.5 & 2.0 & 1.0 & 2.0 & 2.0 & 2.0 & 1.0 & 1.0 & 2.0 & 2.0 & 0.5 & 0.5 & 1.0 & 1.0 & 1.0 & 2.0 & 1.0 & 1.0 & 1.0 & 1.0 & 0.5 & 1.0 & 1.0 & 0.5 \\
\hline A34 & 0.5 & 2.0 & 0.5 & 2.0 & 2.0 & 2.0 & 1.0 & 1.0 & 0.5 & 0.5 & 1.0 & 1.0 & 0.5 & 1.0 & 0.5 & 1.0 & 0.5 & 1.0 & 1.0 & 1.0 & 1.0 & 0.5 & 0.5 & 0.5 & 1.0 & 0.5 \\
\hline A35 & 1.0 & 1.0 & 1.0 & 2.0 & 1.0 & 2.0 & 0.5 & 1.0 & 0.5 & 1.0 & 2.0 & 2.0 & 1.0 & 1.0 & 1.0 & 2.0 & 1.0 & 1.0 & 1.0 & 1.0 & 2.0 & 1.0 & 0.5 & 1.0 & 1.0 & 0.5 \\
\hline A36 & 2.0 & 2.0 & 0.5 & 2.0 & 1.0 & 2.0 & 2.0 & 2.0 & 1.0 & 2.0 & 2.0 & 2.0 & 1.0 & 2.0 & 1.0 & 2.0 & 1.0 & 2.0 & 2.0 & 2.0 & 2.0 & 2.0 & 1.0 & 1.0 & 2.0 & 0.5 \\
\hline A39 & 1.0 & 2.0 & 1.0 & 2.0 & 1.0 & 2.0 & 1.0 & 1.0 & 1.0 & 1.0 & 2.0 & 2.0 & 1.0 & 2.0 & 1.0 & 0.5 & 0.5 & 2.0 & 2.0 & 1.0 & 2.0 & 1.0 & 1.0 & 1.0 & 2.0 & 0.5 \\
\hline A40 & 2.0 & 2.0 & 0.5 & 2.0 & 1.0 & 2.0 & 1.0 & 1.0 & 1.0 & 1.0 & 1.0 & 1.0 & 0.5 & 1.0 & 0.5 & 1.0 & 1.0 & 1.0 & 1.0 & 1.0 & 1.0 & 1.0 & 0.5 & 0.5 & 1.0 & 0.5 \\
\hline A49 & 2.0 & 2.0 & 1.0 & 2.0 & 1.0 & 2.0 & 2.0 & 2.0 & 2.0 & 2.0 & 2.0 & 2.0 & 2.0 & 2.0 & 1.0 & 2.0 & 2.0 & 2.0 & 2.0 & 2.0 & 2.0 & 2.0 & 2.0 & 2.0 & 2.0 & 1.0 \\
\hline $\mathrm{E}$ & 33.0 & 50.0 & 17.5 & 43.5 & 27.5 & 45.5 & 37.0 & 29.5 & 23.0 & 24.5 & 36.5 & 36.5 & 19.5 & 27.5 & 21.0 & 31.0 & 27.0 & 29.5 & 35.5 & 26.5 & 35.0 & 27.0 & 19.5 & 24.0 & 30.0 & 14.7 \\
\hline
\end{tabular}

Risk of the causes of safety accident in management: The risk of A49 is the highest with 1.7. Next, the risk of A07 is 1.5, the risk of A21 is 1.42, the risk of A36 is 1.41, the risk of A24 is 1.31, the risk of A39 is 1.16, the risk of A16 and A17 is 1.13, the risk of A27 and A33 is 1.07 , the risk of $\mathrm{A} 35$ is 1.02 , the risk of $\mathrm{A} 23$ is 1.01 , the risk of $\mathrm{A} 15$ and $\mathrm{A} 31$ is 0.94 , the risk of A11 is 0.93 , the risk of $\mathrm{A} 25$ is 0.91 , the risk of $\mathrm{A} 02$ and $\mathrm{A} 40$ is 0.89 , the risk of $\mathrm{A} 32$ is 0.81 , the risk of $\mathrm{A} 34$ is 0.80 , the risk of $\mathrm{A} 14$ and $\mathrm{A} 19$ is 0.76 , the risk of $\mathrm{A} 18$ is 0.75 , the risk of $\mathrm{A} 10$ is 0.61 , the risk of $\mathrm{A} 13$ is 0.58 and the risk of $\mathrm{A} 04$ is 0.51 .

The following Table 10 is the eigenvector calculated by the pairwise comparison of the risk of the causes of safety accident in management. Table 11 shows the risk of the causes of safety accident belonging to management calculated using the eigenvector in Table 10.
Risk of the causes of safety accident in media: The risk of A37 is the highest with 1.54. Next, the risk of A03 is 0.37 , the risk of $\mathrm{A} 20$ is 1.26 , the risk of $\mathrm{A} 12$ is 0.96 and the risk of A08, A09 and A45 is 0.64. The following Table 12 is the eigenvector calculated by the pairwise comparison of the risk of the causes of safety accident in media. Table 13 shows the risk of the causes of safety accident belonging to media calculated using the eigenvector in Table 12.

Final risk calculation: The final risk for each cause of safety accident was calculated by multiplying the risk of the $4 \mathrm{M}$ item in the upper class by the risk of the cause of safety accident in the lower class. The risk of A49 in management is the highest with 2.77 . Next, the risk of $\mathrm{A} 07$ is 2.45 , the risk of A21 is 2.31 and the risk of A36 is 2.30. The risk of $\mathrm{A} 08, \mathrm{~A} 09$ and $\mathrm{A} 45$ belonging to media was the lowest with 0.43 . 


\section{J. Eng. Applied Sci., 15 (5): 1089-1097, 2020}

Table 11: Risk calculation data of the causes of safety accident in management

\begin{tabular}{|c|c|c|c|c|c|c|c|c|c|c|c|c|c|c|c|c|c|c|c|c|c|c|c|c|c|c|c|}
\hline odes & $\mathrm{A} 02$ & 04 & 07 & 10 & 11 & 13 & 14 & 15 & 16 & A.17 & $\mathrm{A}, 18$ & $\mathrm{~A} 19$ & A.21 & 23 & A.24 & A.25 & A.27 & A.31 & A.32 & A.33 & A.34 & A.35 & 436 & A.39 & $\mathrm{A} 40$ & $\mathrm{~A} 49$ & $\mathrm{R}$ \\
\hline 02 & .03 & & & & & & & & & & & & & & & & & & & & 0.06 & & & & 0.02 & 0.03 & 0.89 \\
\hline & .02 & & & & & & & & & & & & & & & & & & & & & & & & 02 & & \\
\hline & & & & & & & & & & & & & & & & & & & & & & & & & & & \\
\hline & & & & & & & & & & & & & & & & & & & & & & & & & & & \\
\hline & & & & & & & & & & & & & & & & & & & & & 01 & & & & 03 & 107 & 0.93 \\
\hline & 02 & & & & & & & & & & & & & & & & 04 & & & & 01 & & .03 & 02 & 02 & .03 & 0.58 \\
\hline & & & & & & & & & & & & & & & & & & & & & & & & & & & \\
\hline & & & & & & & & & & & & 0.03 & & & & & 07 & & & & & & & & & & \\
\hline & & & & & & & & & & & & & & & & & & & 0.06 & & & & & 0.04 & .03 & .03 & 1.13 \\
\hline & & & & & & & & & & & & & & & & & & & & & & & & & & & 1.13 \\
\hline & & & & & & & & & & & & & 0.03 & & & & & & & & & & & & & & 0.75 \\
\hline & & & & & & & & & & & & & 0.03 & & & & .04 & & & & & & & 0.02 & 05 & 3 & 0.76 \\
\hline & & & & & & & & & & & & & & & & & & & & & & & & & & & \\
\hline & & & & & & & & & & & & & 0 & & & & & & & & & & & & & & 1.01 \\
\hline & & & & & & & & & & & & & & & & & & & & & & & & & 07 & & 1.31 \\
\hline & & & & & & & & & & & & & & & & & & & & & & & & 08 & 03 & 01 & 0.91 \\
\hline & & & & & & & & & & & & & & & & & & & & & & & & & & & \\
\hline & & & & & & & & & & & & & & & & & & & & & & & & & & & 0.94 \\
\hline & & & & & & & & & & & & & & & & & & & & & & & & & 03 & & 0.81 \\
\hline & & & & & & & & & & & & & & & & & & & & & & & & & 03 & 03 & 1.07 \\
\hline & & & & & & & & & & & & & & & & & & & & & & & & & & & \\
\hline & & & & & & & & & & & & & & & & & & & & & & & & & & & \\
\hline & & & & & & & & & & & & & & & & & & & & & & & & & 07 & & 1.41 \\
\hline & 0.03 & & & & & & & & 0.04 & & & & & & & & & & & & & & & 04 & .07 & .03 & 1.16 \\
\hline & & & & & & & & & & & & & & & & & & & & & & & & & & & \\
\hline & 0.06 & & 0.06 & 0.05 & & 0.04 & 0.0 & 0.07 & 0.09 & 0.08 & 0.05 & 0.05 & 0.10 & & 0.05 & 0.06 & & & 0.06 & & 0.06 & & 0.10 & 0.08 & 0.07 & 0.07 & 1.70 \\
\hline
\end{tabular}

A.49 0.06

Table 12: Pairwise comparison and eigenvector of the causes of safety accident in media

\begin{tabular}{|c|c|c|c|c|c|c|c|c|}
\hline Accident codes & $\mathrm{A} 03$ & $\mathrm{~A} 08$ & $\mathrm{~A} 09$ & & $\mathrm{~A} 12$ & $\mathrm{~A} 20$ & A37 & $\mathrm{A} 45$ \\
\hline $\mathrm{A} 03$ & 1.0 & 2.0 & 2.0 & & 2.0 & 1.0 & 1.0 & 2.0 \\
\hline $\mathrm{A} 08$ & 0.5 & 1.0 & 1.0 & & 0.5 & 0.5 & 0.5 & 1.0 \\
\hline $\mathrm{A} 09$ & 0.5 & 1.0 & 1.0 & & 0.5 & 0.5 & 0.5 & 1.0 \\
\hline A12 & 0.5 & 2.0 & 2.0 & & 1.0 & 0.5 & 0.5 & 2.0 \\
\hline $\mathrm{A} 20$ & 1.0 & 2.0 & 2.0 & & 2.0 & 1.0 & 0.5 & 2.0 \\
\hline A37 & 1.0 & 2.0 & 2.0 & & 2.0 & 2.0 & 1.0 & 2.0 \\
\hline A45 & 0.5 & 1.0 & 1.0 & & 0.5 & 0.5 & 0.5 & 1.0 \\
\hline Eigenvector $(\mathrm{E})$ & 5.0 & 11.0 & 11.0 & & 8.5 & 6.0 & 4.5 & 11.0 \\
\hline Accident codes & $\mathrm{AO3}$ & $\mathrm{A} 08$ & $\mathrm{~A} 09$ & $\mathrm{~A} 12$ & $\mathrm{~A} 20$ & $\mathrm{~A} 37$ & $\mathrm{~A} 45$ & Risk (R) \\
\hline $\mathrm{AO3}$ & 0.20 & 0.18 & 0.18 & 0.24 & 0.17 & 0.22 & 0.18 & 1.37 \\
\hline A08 & 0.10 & 0.09 & 0.09 & 0.06 & 0.08 & 0.11 & 0.09 & 0.63 \\
\hline $\mathrm{A} 09$ & 0.10 & 0.09 & 0.09 & 0.06 & 0.08 & 0.11 & 0.09 & 0.63 \\
\hline A.12 & 0.10 & 0.18 & 0.18 & 0.12 & 0.08 & 0.11 & 0.18 & 0.96 \\
\hline $\mathrm{A} 20$ & 0.20 & 0.18 & 0.18 & 0.24 & 0.17 & 0.11 & 0.18 & 1.26 \\
\hline A37 & 0.20 & 0.18 & 0.18 & 0.24 & 0.33 & 0.22 & 0.18 & 1.54 \\
\hline $\mathrm{A} 45$ & 0.10 & 0.09 & 0.09 & 0.06 & 0.08 & 0.11 & 0.09 & 0.63 \\
\hline
\end{tabular}

Table 14: Final risk of the causes of safety accident

\begin{tabular}{|c|c|c|c|}
\hline \multirow[b]{2}{*}{$4 \mathrm{M}$ items/Risk $(\mathrm{A})$} & \multirow[b]{2}{*}{ Accident codes } & \multicolumn{2}{|c|}{ Causes of safety accident } \\
\hline & & Risk (B) & Final risk $(A \times B)$ \\
\hline \multirow[t]{10}{*}{$\operatorname{Man}(0.96)$} & $\mathrm{A} 01$ & 0.85 & 0.82 \\
\hline & A05 & 0.78 & 0.75 \\
\hline & A 30 & 1.25 & 1.20 \\
\hline & A38 & 1.09 & 1.05 \\
\hline & A42 & 0.73 & 0.70 \\
\hline & A43 & 1.10 & 1.06 \\
\hline & A44 & 0.56 & 0.54 \\
\hline & A46 & 1.05 & 1.01 \\
\hline & A.47 & 1.34 & 1.29 \\
\hline & A48 & 1.26 & 1.21 \\
\hline \multirow[t]{6}{*}{ Machine $(0.82)$} & $\mathrm{A} 02$ & 0.70 & 0.57 \\
\hline & A22 & 0.77 & 0.63 \\
\hline & A26 & 0.66 & 0.54 \\
\hline & A.28 & 1.32 & 1.08 \\
\hline & A29 & 1.32 & 1.08 \\
\hline & A41 & 1.21 & 0.99 \\
\hline \multirow[t]{17}{*}{ Management (1.63) } & $\mathrm{A} 02$ & 0.89 & 1.45 \\
\hline & $\mathrm{A} 04$ & 0.51 & 0.83 \\
\hline & A07 & 1.50 & 2.45 \\
\hline & A10 & 0.61 & 0.99 \\
\hline & A11 & 0.93 & 1.52 \\
\hline & A13 & 0.58 & 0.95 \\
\hline & A.14 & 0.76 & 1.24 \\
\hline & A15 & 0.94 & 1.53 \\
\hline & A.16 & 1.13 & 1.84 \\
\hline & A17 & 1.13 & 1.84 \\
\hline & A18 & 0.75 & 1.22 \\
\hline & A.19 & 0.76 & 1.24 \\
\hline & A.21 & 1.42 & 2.31 \\
\hline & A23 & 1.01 & 1.65 \\
\hline & A.24 & 1.31 & 2.14 \\
\hline & A25 & 0.91 & 1.48 \\
\hline & A27 & 1.07 & 1.74 \\
\hline
\end{tabular}




\begin{tabular}{|c|c|c|c|}
\hline \multirow[b]{2}{*}{ 4M items/Risk (A) } & \multirow[b]{2}{*}{ Accident codes } & \multicolumn{2}{|c|}{ Causes of safety accident } \\
\hline & & Risk (B) & Final risk $(A \times B)$ \\
\hline \multirow{16}{*}{ Media $(0.69)$} & A31 & 0.94 & 1.53 \\
\hline & A32 & 0.81 & 1.32 \\
\hline & A.33 & 1.07 & 1.74 \\
\hline & A34 & 0.80 & 1.30 \\
\hline & A.35 & 1.02 & 1.66 \\
\hline & A.36 & 1.41 & 2.30 \\
\hline & A.39 & 1.16 & 1.89 \\
\hline & $\mathrm{A} 40$ & 0.89 & 1.45 \\
\hline & A49 & 1.70 & 2.77 \\
\hline & $\mathrm{A} 03$ & 1.37 & 0.95 \\
\hline & $\mathrm{A} 08$ & 0.63 & 0.43 \\
\hline & $\mathrm{A} 09$ & 0.63 & 0.43 \\
\hline & $\mathrm{A} 12$ & 0.96 & 0.66 \\
\hline & $\mathrm{A} 20$ & 1.26 & 0.87 \\
\hline & A.37 & 1.54 & 1.06 \\
\hline & A45 & 0.63 & 0.43 \\
\hline
\end{tabular}

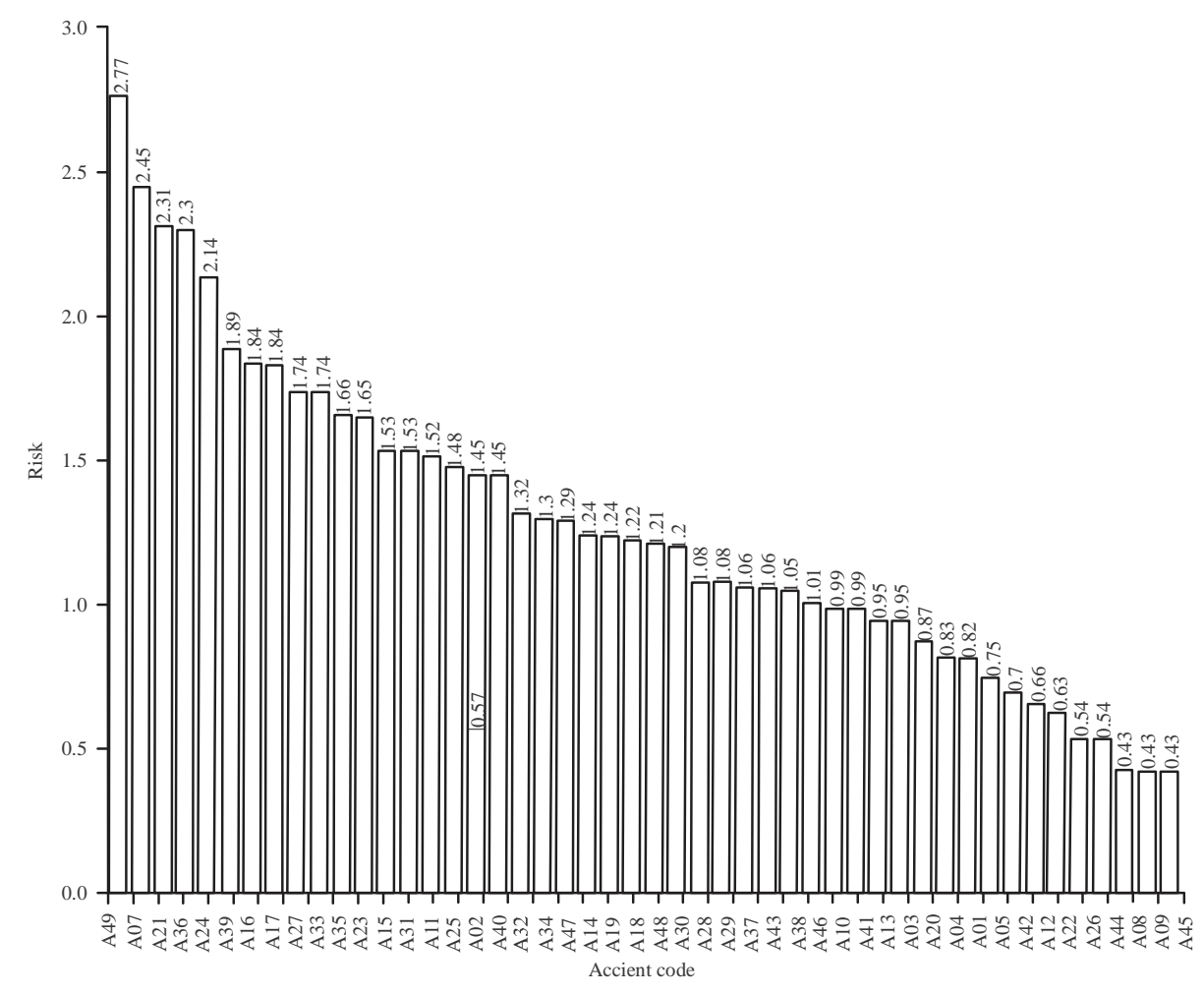

Fig. 2: A graph of the final risk of the causes of safety accident in order of high risk

The causes of safety accident with a final risk of $<0.5$ are A08, A09 and A45. The causes of safety accidents with a final risk of $<0.5$ accounted for $6.1 \%$ of all causes of safety accident. A10, A41, A13, A03, A20, A04, A01, $\mathrm{A} 05, \mathrm{~A} 42, \mathrm{~A} 12, \mathrm{~A} 22, \mathrm{~A} 02, \mathrm{~A} 26$ and $\mathrm{A} 44$ are the causes of safety accident with a final risk of $<0.5$ and $<1.0$. The causes of safety accident with a final risk of 0.5 and $<1.0$ accounted for $28.6 \%$ of all causes of safety accident. Causes of safety accident with a final risk of 1.0 and $<2.0$ include A39, A16, A17, A27, A33, A35, A23, A15, A31, $\mathrm{A} 11, \mathrm{~A} 25, \mathrm{~A} 02, \mathrm{~A} 40, \mathrm{~A} 32, \mathrm{~A} 34, \mathrm{~A} 47, \mathrm{~A} 14, \mathrm{~A} 19, \mathrm{~A} 18$, A48, A30, A28, A29, A37, A43, A38 and A46. The causes of safety accident with a final risk of $>1.0$ and $<2.0$ accounted for $55.1 \%$ of all causes of safety accident. The causes of safety accident with a final risk of level of 2.0 or higher are A49, A07, A21, A36 and A24. The causes of safety accident with a final risk of level of 2.0 or higher accounted for $10.2 \%$ of all causes of safety accident (Fig. 2).

\section{CONCLUSION}

Korea has carried out various activities to prevent safety accidents occurring at construction sites. However, despite the government and private safety accident prevention activities, 25,649 workers were injured in the 
construction industry in 2018. In 2018, the number of casualties in the construction industry is the highest among industries. Such a high number of casualties represents a limitation on existing methods of preventing safety accidents. Therefore, a new approach to current safety accident prevention activities is needed (Kia and Park, 2014).

The purpose of this study was to analyze the risk of the causes of safety accidents in construction sites in order to enhance the effectiveness of safety management activities. The risk of safety accidents caused by 'Violation of safety regulations or guidelines (A49)', 'Inadequate communication with workers (A07)', 'Inappropriate method statement (A21)', 'Lack of training and education on manpower needs (A36)' and 'Inappropriate recognition and assessment of on-site risk factors (A24)' was analyzed to be high. On the other hand the risk of safety accidents due to 'Inadequate conditions above ground and underground (A08)', 'Inadequate topography (A09)' and 'Unfavorable climate conditions (A45)' was analyzed not to be high. 'Violation of safety regulations and guidelines (A49)', 'Inadequate communication with workers (A07)', 'Inappropriate method statement (A21)', 'Lack of training and education on manpower needs (A36)' and 'Inappropriate recognition and assessment of on-site risk factors (A24) with high final risk belong to management among $4 \mathrm{Mitems}$. On the other hand, 'Inadequate conditions above ground and underground (A08)', 'Inadequate topography (A09)' and 'Unfavorable climate conditions (A45)' which are not at high final risk, belong to media among 4M items.

Therefore, in order to prevent safety accidents, it is necessary to upgrade safety management by additionally arranging safety management personnel and strengthening safety education in terms of management with the most high-risk items.

The results of this study can be used to adjust the timing, frequency and level of supervision according to the risk level of the causes of safety accident. In addition, centralized management of the causes of safety accident with high final risk can increase the efficiency of construction safety management.

\section{ACKNOWLEDGEMENT}

This study was supported by research fund from Songwon University 2019 (C2019-06).

\section{REFERENCES}

Kia, S. and N. Park, 2014. Research on the Establishment of contractor centered safety management system to reduce construction disaster. J. Korean Soc. Disaster Inf., 10: 503-510.

MEL., 2019. The status of industrial accidents 2018. Ministry of Employment and Labor, Sejong City, Republic of Korea.

Matthews, R. and J. Ageros, 2008. Health and Safety Enforcement: Law and Practice. 2nd Edn., Oxford University Press, Oxford, UK., ISBN: 13: 9780199212866, Pages: 703.

Paek, C.H. and U.R. Cho, 2015. A study on the optimization effectiveness of risk assessment in construction industry. J. Korea Saf. Manage. Sci., 17: $15-22$.

Park, J.H., 2010. Analysis of the frequency and intensity of construction accidents. Ph.D. Thesis, Department of Architectural Engineering, Incheon National University, Incheon, South Korea.

Saaty, T.L. and G. Hu, 1998. Ranking by eigenvector versus other methods in the analytic hierarchy process. Appl. Math. Lett., 11: 121-125.

Seo, S.H., 2013. A study on hazard managements of steel manufacturing industry using risk assessment technique. Ph.D Thesis, Department of Safety Engineering, Dongguk University SeoulCampus, Seoul, South Korea. 